\title{
Command Professional Edition: Initial insights of a commercial military operational modelling and simulation tool
}

\author{
S. Hagley, E. H. S. Lo, P. J. Hoek, A. Donohoo, and J. Peacock \\ Defence Science and Technology Group, Department of Defence \\ Email: james.peacock@dst.defence.gov.au
}

\begin{abstract}
Computer modelling and simulation can support decision making for military organisations. Command: Professional Edition (Command PE) is a commercially available software package that models military warfighting scenarios at the operational-tactical level of resolution. Its strength as an analytical tool is the ability to "drag and drop" entities (military platforms, radars, air bases, etc.) into scenarios, customise loadouts (e.g. weapon mixes on fighter aircraft) and modify the existing database (which already contains over 11,000 platforms) with experiment specific data. The use of Command PE as a human-in-the-loop war gaming tool is its primary purpose and has been documented elsewhere. But, the implementation of its Monte Carlo features to perform simulation experiments has not been examined. This paper aims to report an exemplar analysis using a vignette from a historical warfighting scenario to assess how Command PE could be leveraged to support simulation experiments.
\end{abstract}

We examined the effect of different weapon loadouts on an air task group as it attacked a naval task group. The scenario employed was a replication from the Falklands War. Four Argentinian fighter aircraft attacked two United Kingdom (UK) ships. Historically, both ships were struck by bombs from Argentinian aircraft and one ship was destroyed. The Monte Carlo tool in Command PE was implemented by creating two scenario files to represent the different design points for the experiment (six vs eight bombs for the second Argentinian air task group). One hundred iterations per design point were captured. Various statistical tests identified the number of bombs available increased the chance of any UK ships being destroyed (31\% to 58\%) but had a negligible effect on the chance of any Argentinian aircraft being destroyed (84\% to $87 \%)$.

Users that intend to run experiments (both simulation and human in the loop experiments) with their own data sources must have an understanding of the adjudication system within Command PE. This will enable users to incorporate experiment specific data by modifying the Command PE database (noting its defined schema) to appropriately model the warfighting scenarios. For example, some Command PE adjudication is based on probabilities that are defined within the database. Effectors, such as guided missiles, have a base probability of hit that is modified according to the platform it is targeting. In our scenario, the probability of hit for UK surface-to-air missiles on Argentinian aircraft was modified by speed, agility, altitude, angle of flight, and platform shape. These parameters were explicitly represented in the database, and incorporating experiment specific data for guided missiles must adhere to this schema. Users should also consider verification and validation of Command PE simulation outputs with appropriate, authoritative models and datasets.

Command PE can be used to perform simulation experiments that have a small number of design points. Our implementation of Command PE to perform simulation experiments is not recommended when a high number of design points are required. This is due to the approach we implemented whereby individual scenario files were manually created for each design point. Further, there is a lack of any ability to implement common random numbers. While Command PE is very much a human-in-the-loop proposition, it can be used for closedloop quantitative analysis. But the ability to perform factorial simulation experiments with a high number of factors requires further work. There are other avenues that might be leveraged to execute a high factor simulation experiment with Command PE, including using the underlying Lua scripting.

Keywords: Modelling and simulation, war gaming, design of experiments, data analysis, military strategy 
Hagley et al., Command Professional Edition: Initial insights of a commercial military operational modelling and simulation tool

\section{INTRODUCTION}

Computer modelling and simulation can support strategic decision making of military organisations (Davis, Kulick \& Egner, 2005). The selection and implementation of a simulation package to support strategic decision making is no trivial task and must be made in reference to the analytical question. This requires an assessment of the fitness for purpose of the simulation package by considering various dimensions before any outputs can be trusted. Not all dimensions are equally important for determining the suitability of a simulation package. For military operations analysis, initial steps to assess the suitability of a simulation package include the warfighting domain(s) represented, the level of resolution (e.g. campaign or physics-based), and the validity of the model to represent factors of interest.

There are many computer modelling and simulation packages are available to perform military operations analysis. Table 1 identifies, from a selection simulation packages, each package is unique in the domains they model and the level of warfighting represented. Additional factors to consider when selecting a simulation package include the ability to view/inspect source code, the cost (in terms of time and/or dollars) required to develop the models or integrate experiment specific data, and the ability to perform simulation experiments or other desired analytical approaches. Lastly, the simulation package must pass verification and validation (Sargent, 2013) and have the ability to be integrated within a desired analytical campaign.

Table 1. A survey of relevant simulation packages to support military operations analysis. Each simulation package is unique in the domains they model, the level of warfighting, and the origins of the package.

\begin{tabular}{|c|c|c|c|c|c|c|c|c|}
\hline \multirow[b]{2}{*}{ Simulation } & \multicolumn{3}{|c|}{ Domain } & \multicolumn{2}{|c|}{ Level } & \multirow[b]{2}{*}{ Country } & \multirow[b]{2}{*}{$\mathrm{G} / \mathrm{P}$} & \multirow[b]{2}{*}{ Title / Use } \\
\hline & Air & Land & Maritime & Campaign & Mission & & & \\
\hline AFSIM & $\checkmark$ & Limited & $\checkmark$ & & $\checkmark$ & US & G & $\begin{array}{l}\text { Advanced Framework for Simulation, Integration \& } \\
\text { Modelling }\end{array}$ \\
\hline CLARION & $\checkmark$ & $\checkmark$ & & $\checkmark$ & & UK & G & Combined Land Air Representation of Integrated Ops \\
\hline COMAND & $\checkmark$ & & $\checkmark$ & $\checkmark$ & & UK & G & C3 Oriented Model of Naval and Air Domains \\
\hline $\begin{array}{l}\text { Combat } \\
\text { XXI }\end{array}$ & & $\checkmark$ & & & $\checkmark$ & US & $\mathrm{P}$ & Combined Arms Analysis Tool for the 21st Century \\
\hline $\begin{array}{l}\text { Command } \\
\text { PE }\end{array}$ & $\checkmark$ & $\checkmark$ & $\checkmark$ & & $\checkmark$ & UK & $P$ & Extended from CMANO by Matrix Games \\
\hline EADSIM & $\checkmark$ & Limited & & & $\checkmark$ & US & $\mathrm{P}$ & Extended Air Defense Simulation \\
\hline GCAM & $\checkmark$ & $\checkmark$ & $\checkmark$ & $\checkmark$ & $\checkmark$ & US & $\mathrm{P}$ & Developed by Systems Planning and Analysis, Inc. \\
\hline JFOrCE & $\checkmark$ & Limited & $\checkmark$ & $\checkmark$ & & $\mathrm{AU}$ & G & Joint Future OpeRating Concept Explorer \\
\hline JWARS & $\checkmark$ & $\checkmark$ & $\checkmark$ & & & US & G & Joint Warfare System that replaced TACWAR \\
\hline PAXSEM & $\checkmark$ & $\checkmark$ & & & $\checkmark$ & Germany & $\mathrm{G} / \mathrm{P}$ & Agent-based with psychological modelling \\
\hline STORM & $\checkmark$ & $\checkmark$ & $\checkmark$ & $\checkmark$ & & US & $\mathrm{G} / \mathrm{P}$ & Synthetic Theater Operations Research Model \\
\hline
\end{tabular}

Legend: US $=$ United States of America, $\mathrm{UK}=$ United Kingdom, AU = Australia, $\mathrm{G}=$ Accessible to government employees, $\mathrm{P}=$ Proprietary owned.

Command: Professional Edition (Matrix Games LLC: Surrey, United Kingdom) is one of the military simulation packages listed in Table 1. Command: Professional Edition, hereafter referred to as Command PE, is an extension to the publicly available video game, Command: Modern Naval and Air Operations (referred to as CMANO in public forums) where players control military forces at the tactical-operational level. The user has control over entities such as platforms, task groups, weapon loadouts, emissions, flight paths, and weapons release doctrine. Command PE has additional features including scenario editor, Monte-Carlo analysis, and database editor. Due to the available entities that come with the package and the ease of creating scenarios by 'dragging and dropping' entities onto the map, there is potential that Command PE could be leveraged to create a quick and relatively inexpensive way to perform analysis to support decision making.

The aim of this paper is to report on a pilot study using Command PE and discuss our initial insights on its suitability as a tool to support decision making for military operations. While it has been shown that Command PE can be used as a human-in-the-loop war gaming tool (Georgetown University Wargaming Society, 2020), this review focused on using the Monte Carlo mode of Command PE to perform a simulation experiment. This was achieved by using an exemplar analysis using a vignette from a historical warfighting scenario, the Falklands War. This paper makes no intent to comment on the ability of Command PE to reproduce real-world 
Hagley et al., Command Professional Edition: Initial insights of a commercial military operational modelling and simulation tool

events, but does provide an insight into the underlying models of the simulation to inform how experiment specific data could be ingested.

\section{METHOD}

The Falklands War involved Argentina and the United Kingdom (UK) between 18 March and 22 June, 1982. This war was a dispute over the sovereignty of the Falkland Islands, an island chain south-east of Argentina. The war consisted of numerous battles among air, land and naval units from both sides. In this paper, the simulated scenario was the conflict that occurred on 25 May, 1982. This mission involved two groups of two Argentinian fighter aircraft (A-4P Skyhawks) attacking two UK ships (HMS Coventry, DDG and HMS Broadsword, FFG) (Figure 1). Historically, both UK ships HMS Broadsword and HMS Coventry were struck by the bombs as the Argentinian aircraft retreated (Anderson, 2014; Privatsky \& Thompson, 2016). HMS Coventry was sunk while HMS Broadsword recovered. The Sea of Fire scenario included with Command PE (version 1.15, Matrix Games Ltd.; Surrey, United Kingdom) was employed as a representation of this historical vignette.

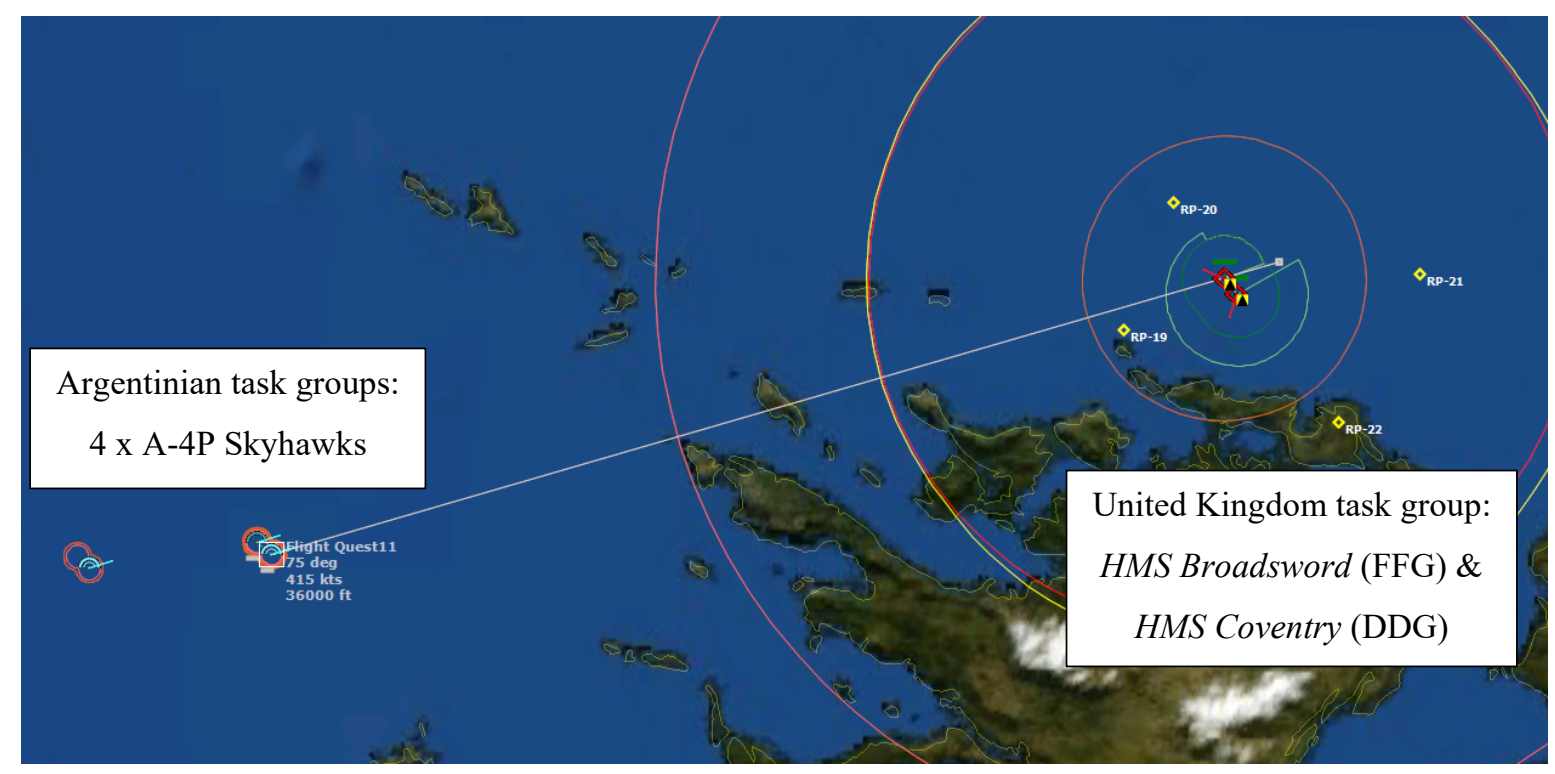

Figure 1. Screenshot from Command PE displaying the Argentinian task groups (blue) and United Kingdom task group (red)

In the simulated scenario, four Argentinean aircraft were formed into two air task groups and attacked the two UK ships (Figure 1). The behaviours of the Argentinian aircraft were programmed via building a "strike mission". As shown in Figure 1, the strike area was defined by the yellow tick marks surrounding the UK ships. The flight characteristics (speed, altitude) were then set for the flight toward this area and then within this area. Likewise, the behaviours for the UK ships were set on a "patrol mission" within the same defined area. Given the intent of this paper to explore the ability to perform a simulation experiment, varying the number of Argentinian bombs was arbitrarily chosen. Therefore, a comparison was made between the quantity of bombs available for the second Argentinian task group (six versus eight bombs) while all other factors were held constant. The constant variables included task group composition (e.g. aircraft type, additional platforms available for the task groups), weapon type(s), flight path (speed, altitude), sensor emission and weapons release doctrine (Table 2 , Table 3 ).

A Monte-Carlo analysis was performed to capture 100 iterations for each design point (6 bombs vs. 8 bombs). This was achieved by manually creating two scenario files whereby the different weapon loadouts were saved and executed using the graphical user-interface Monte Carlo tool within Command PE. Visual inspection of the scenario execution was performed for each condition to verify the behaviours of the entities prior to MonteCarlo analysis execution. Stochasticity was introduced by using "missions" within Command PE. This included defining a strike area and a patrol area for the Argentinian and UK platforms, respectively. Within these defined areas, the user specifies some kinematics (speed, altitude), however the path of the platforms within the defined area is computer generated. The use of common random numbers (also referred to as common random seeds between the conditions) (Law, 2015) was not employed as this feature was not available. Data were saved in "light" format. This includes only weapons expenditures and platform losses for the present scenario and saving 
Hagley et al., Command Professional Edition: Initial insights of a commercial military operational modelling and simulation tool

in a non-tabulated text file format. It was possible to capture timed interval recordings of variables including positions of platforms and missiles and sensor detections into a tabulated format. However, pilot runs of saving this data were costly in terms of data storage (two minutes of scenario was about 350 megabytes) and added to scenario run time. If necessary, this data could be captured to aid in answering research questions.

Table 2. Input factors for Argentinian aircraft. Note that weapon loadout for task group 2 was varied for the experiment.

\begin{tabular}{llc}
\hline Factor & Description & $\begin{array}{l}\text { Constant/ } \\
\text { varied }\end{array}$ \\
\hline Weapon loadout (total for task group 1) & $2 \times 1,000$ lb general purpose bomb & Constant \\
Weapon loadout (total for task group 2) & 6 vs. 8 x Mark 82500 lb Snake Eye bomb & Varied \\
Speed & 415 knots & Constant \\
Altitude & $36,000 \mathrm{ft}$ & Constant \\
Weapons release doctrine & Fire at targets positively identified as hostile & Constant \\
Sensor emissions & Radar active & Constant \\
\hline
\end{tabular}

Table 3. Factors held constant for United Kingdom ships

\begin{tabular}{ll}
\hline Factor & Description \\
\hline Speed & 5 knots \\
Weapons release doctrine & Fire at targets positively identified as hostile \\
Sensor emissions & Radars active \\
Primary defensive weapon (DDG) & $1 \times$ Sea Dart Mod 0 \\
Primary defensive weapon (FFG) & $1 \times$ Sea Wolf Blk 1 \\
\hline
\end{tabular}

To compare the operational differences between the two weapon loadouts, we included dependent variables of the number of platforms of the UK ships and Argentinian aircraft destroyed. The maximum number of platforms destroyed was two and four for the UK and Argentina, respectively. A Python-based parser was developed to process the unstructured exported text data for analysis. Contingency tables were produced to assess the effect of the weapons loadouts on platforms destroyed. Various statistical tests were performed to assess if the number of bombs affected the number of platforms destroyed. A Chi-Squared test was used to compare the frequency of the outcomes (alpha level set at .05). The odds ratio $(O R)$ and $95 \%$ confidence interval $(C I)$ were calculated to measure the effect size of weapon quantity on the platforms destroyed. Additionally, the outcomes were expressed as percentages, e.g. HMS Coventry was sunk $38 \%$ of the time, to aid with interpretation.

\section{RESULTS}

Monte Carlo simulation identified that increasing the number of bombs available on the Argentinian aircraft increased the number of UK ships destroyed (Table 4). The frequency of at least one UK ship being destroyed from the 100 scenario runs for each condition increased from $31 \%$ to $58 \%$ as bomb numbers increased. Between the conditions of eight versus six bombs, the $O R$ for any number of UK ships being destroyed was 3.07 (95\% $C I=1.72-5.49)$. This indicated the odds of any UK ship being destroyed was 3.07 times greater when Argentina had eight compared to six bombs. Likewise, the Chi-Square test of independence, Chi-Squared (2, $N=200)=14.76, p<.01$, indicated the distribution of UK ships destroyed was significantly different between the number of bombs available.

The number of bombs available on the Argentinian aircraft had a negligible influence on the quantity of Argentinian aircraft destroyed. The frequency of any number of Argentinian jets destroyed increased from $84 \%$ to $87 \%$ (Table 5). However, the statistical tests indicate that this difference was negligible. The $O R$ was 1.24 $(95 \% C I=0.58-2.81)$ and Chi-Squared $(4, N=200)=2.62, p=.62$. 
Hagley et al., Command Professional Edition: Initial insights of a commercial military operational modelling and simulation tool

Table 4. Contingency table for the frequency of UK ships destroyed across the two conditions of differing bomb counts. Values represent the count of the outcomes across the 100 iterations for each condition.

\begin{tabular}{lccc}
\hline Condition & \multicolumn{3}{c}{ Number of UK ships destroyed } \\
& 0 & 1 & 2 \\
\hline Six bombs & 69 & 28 & 3 \\
Eight bombs & 42 & 52 & 6 \\
\hline
\end{tabular}

Table 5. Contingency table for the frequency of Argentinian aircraft destroyed across the two conditions of differing bomb counts. Values represent the count of the outcomes across the 100 iterations for each condition.

\begin{tabular}{lccccc}
\hline \multirow{2}{*}{ Condition } & \multicolumn{5}{c}{ Number of Argentinian aircraft destroyed } \\
& 0 & 1 & 2 & 3 & 4 \\
\hline Six bombs & 16 & 51 & 26 & 6 & 1 \\
Eight bombs & 13 & 56 & 28 & 3 & 0 \\
\hline
\end{tabular}

\section{DISCUSSION}

The aim of this paper was to review the use of Command PE as a tool to perform operations analysis. This was achieved by performing an exemplar analysis to provide a basis for assessing the tool in its ability to perform a simulation experiment. The primary outcome of this report was that we were able to successfully perform an analysis comparing alternate weapon loadouts with a historical scenario. We discuss how a simulation experiment might be performed and provide an insight into some of the models within the simulation. While Command PE did replicate the historical outcome in some scenario iterations (one ship destroyed), the results from this paper should not be used to promote 'validity' of the tool. This is because no attempt was made to validate the underlying models.

The provision of two additional bombs for the Argentinian aircraft increased the number of UK ships destroyed (Table 4). Within the simulation, the interaction between the Argentinian aircraft and UK ships was determined by a series of events, some being probabilistic. Chronologically within the scenario, the Argentinian aircraft detected the location of the UK ships, released all bombs and retreated. Likewise, the UK ships detected the Argentinian aircraft and bombs, and fired all surface-to-air missiles in an attempt to destroy the aircraft. The outcomes for the interaction of platforms and guided missiles were determined from a baseline probability of hit by the effector (i.e. missile) and this probability was modified by characteristics of the affected (opposing) platform. The modifiers for the Argentinian aircraft which reduced the probability of hit included speed, agility, altitude, angle of flight, and platform shape (Table 6). The additional bombs afforded the Argentinian aircraft two more opportunities to target the UK ships.

The additional bombs on the Argentinian aircraft made a negligible difference to the probability of Argentinian aircraft destroyed (Table 5). While it is possible the extra time required for Argentinian aircraft to release the additional bombs might have afforded more opportunities for the UK ships to attack them, visual inspection of the simulation runs and the results (Table 5) indicated this was negligible. This could be due to a minimal amount of extra time required for the Argentinian aircraft to release the additional two bombs and/ or UK ships depleting stocks of the surface-to-air-missiles under both experimental conditions.

Ingesting experiment specific data, and validation and verification of Command PE simulation outputs must be made in reference to the modelling framework within the simulation. Table 6 shows that the adjudication of guided missile and airplanes used a base probability of hit modified by parameters of the attacked platform. Likewise, the unguided bombs appear to use a different adjudication method (Table 6). Additionally, post-hoc inspections of sensor detections (represented as binary successful / unsuccessful) were influenced by distance and emissions. Users should be aware of the various adjudication models within Command PE. This information can inform how experiment specific data can be ingested and how to appropriately perform validation and verification of simulation outputs. Editing the Command PE database is one approach to implement experiment specific data. However, edits must adhere to the schema of the database. Guided 
Hagley et al., Command Professional Edition: Initial insights of a commercial military operational modelling and simulation tool

missiles require specification of a base probability of hit and platform-specific modifiers. Validation and verification of simulation outputs could be performed in reference to the parameters within the adjudication models.

Table 6. Extracts from game logs for adjudication of effector to platform interactions

\begin{tabular}{|c|c|c|}
\hline Effector & Targeted platform & Command PE adjudication \\
\hline $\begin{array}{l}\text { United Kingdom } \\
\text { surface-to-air } \\
\text { missile (Sea Dart } \\
\text { Mod 0) }\end{array}$ & $\begin{array}{l}\text { Argentinian aircraft } \\
\text { (A-4P Skyhawk) }\end{array}$ & $\begin{array}{l}\text { Weapon: Sea Dart Mod } 0 \text { \#192 is attacking A-4P Skyhawk } \\
\text { [A-4B Caza] with a base PH of } 70 \% \text {. A-4P Skyhawk has } \\
\text { nominal agility: } 3 \text {, adjusted for altitude: } 2.5 \text {. Agility adjusted } \\
\text { for proficiency (Regular): } 2 \text {. Aircraft has a weight fraction } \\
\text { of } 0.31 \text { - Agility adjusted to } 1.63 \text {. Agility adjusted for head- } \\
\text { on impact effect: } 1 \text {. Final agility modifier: }-10 \% \text {. Final PH: } \\
60 \% \text {. Result: } 71 \text { - MISS }\end{array}$ \\
\hline $\begin{array}{l}\text { United Kingdom } \\
\text { guns on ship }\end{array}$ & $\begin{array}{l}\text { Argentinian aircraft } \\
\text { (A-4P Skyhawk) }\end{array}$ & $\begin{array}{l}\text { Gun }(20 \mathrm{~mm} / 70 \text { Oerlikon Mk7 Burst [ } 20 \text { rnds]) is attacking } \\
\text { A-4P Skyhawk with a base-Ph of } 0.3 \% \text {. Base-Ph adjusted } \\
\text { for distance: } 0.3 \% \text {. A-4P Skyhawk has nominal agility: } 3 \text {, } \\
\text { adjusted for altitude: } 3 \text {. Agility adjusted for proficiency } \\
\text { (Regular): } 2.4 \text {. Aircraft has a weight fraction of } 0.11 \text { - } \\
\text { Agility adjusted to } 2.25 \text {. Agility adjusted for tail-on impact } \\
\text { effect: } 1.1 \text {. Final agility modifier: }-11 \% \text {. Final Ph: } 1 \% \text {. } \\
\text { Result: } 14 \text { - MISS }\end{array}$ \\
\hline $\begin{array}{l}\text { Argentinian } \\
\text { general purpose } \\
\text { bomb (Mk82 } \\
\text { 500lb Snakeeye) }\end{array}$ & $\begin{array}{l}\text { United Kingdom ship } \\
\text { (HMS Coventry) }\end{array}$ & $\begin{array}{l}\text { Weapon: Mk82 500lb Snakeeye missed HMS Coventry by } \\
158 \mathrm{ft}\end{array}$ \\
\hline $\begin{array}{l}\text { Argentinian } \\
\text { general purpose } \\
\text { bomb (Mk13 } \\
\text { 1000lb GPB) }\end{array}$ & $\begin{array}{l}\text { United Kingdom ship } \\
\text { (HMS Broadsword) }\end{array}$ & $\begin{array}{l}\text { Weapon: Mk13 1000lb GPB missed HMS Broadsword by } \\
390 \mathrm{ft}\end{array}$ \\
\hline
\end{tabular}

It is possible to build scenarios that contain more platforms that interact over successive events to be reflective of a large military operation. This would involve exploring and coding divergent courses of action. While the present analysis could be described as a tactical vignette due to the number of platforms included in the simulation, there is scope for further analysis to represent a broader military operation. In the Falklands War, historically HMS Broadsword and HMS Coventry were damaged. Our analysis showed that with the original six bombs, the probability of no UK ships being destroyed was $69 \%$ (Table 4); this is the most-likely outcome. If the outcomes from this analysis were integrated into a broader military campaign to represent the entire Falklands War, one might choose to select the most-likely outcome as the basis for further progression within the campaign. This would include developing subsequent courses-of-action to reflect HMS Broadsword and $H M S$ Coventry being available for future operations as part of the Falklands War.

There are many warfare situations where platforms aren't dynamically interacting with the opposition (e.g. waiting for a sensor detection to exceed a certain threshold during anti-submarine warfare). Similarly, there are situations where platforms are idle for a long period of time (e.g. weeks if they are waiting for supplies). These scenarios do not necessarily need to be simulated and the user can save on computational time. By using a combination of tools, it is possible to jump forward to key interactions that can be analysed using the Monte Carlo tool in Command PE. The primary analytical mode available in Command PE, of human-in-the-loop war gaming (with the option to increase gameplay speed), is an alternate tool where various operational decisions and courses-of-action could be identified to inform subsequent Monte Carlo analysis. This issue, however, of having to code or model complex interactions over a long duration is not unique to Command PE but is a characteristic of many military simulations.

If many parameters needed to be explored at various levels, our (rudimentary) implementation of the MonteCarlo data collection and analysis would become manually intensive. Efficiently implementing the various 
Hagley et al., Command Professional Edition: Initial insights of a commercial military operational modelling and simulation tool

approaches for simulation experiments (e.g. factorial designs, fractional-factorial designs, nearly-orthogonal Latin hypercubes) requires the ability to program or import tabulated data that specifies the design points across the factors of interest (Kleijnen, Sanchez, Lucas \& Cioppa, 2005; Sanchez, Sanchez \& Wan, 2020). The approach used in this study would make performing a factorial design with a high number of factors cumbersome and is not recommended; each design point would have to be developed into a separate scenario file.

Command PE has two additional modes to execute Monte Carlo simulation: accessing Lua scripting via the application program interface and command line interface to load scenario files via a headless graphical user interface which uses parallel computing. These modes provide opportunities to support simulation experiments by linking alternate programming languages (e.g. Python, R or Excel VBA) and reduce the time to execute simulation runs. Our initial testing (including using version 2.0 of Command PE) identified limitations in how these modes could be implemented to perform a factorial simulation experiment, but they may be more effective than the method used in the present paper. For example, these modes still had no easily ingestible means of varying parameter levels.

This review was limited in that it explored a historical scenario that was largely kinetic. As future operations are likely to include non-kinetic interactions, this paper cannot comment on the ability of Command PE to model these. There are many non-kinetic platforms available for deployment within the Command PE database, such as electronic warfare fighter aircraft, jamming and space-based capabilities. It is recommended that future work explore the ability of Command PE to model non-kinetic operations.

\section{CONCLUSION}

Command PE can be used to perform simulation experiments. In this paper, we reported a simulation experiment using a historical military scenario whereby the number of weapons available to an air task group influenced the number of opposition's ships destroyed. Only one factor within the experiment was adjusted. It is not recommended to implement the method described in this paper to perform simulation experiments with a high number of design points (e.g. factorial designs, nearly-orthogonal Latin hypercubes). We also present some of the adjudication models within Command PE, which users must be aware of if they are to incorporate experiment specific data and perform validation and verification of simulation outputs. While Command PE is very much a human-in-the-loop proposition, it can be used for quantitative analysis. The ability to perform high factorial designs is still a work-in-progress. Furthermore, any simulation outputs must go through appropriate validation prior to being used to support decision-making.

\section{REFERENCES}

Anderson, D., 2014. The Falklands War 1982: Bloomsbury Publishing, New York.

Georgetown University Wargaming Society, 2020. The Analytical Utility of Command PE: Perspectives from Two Practitioners. Accessed from https://www.youtube.com/watch?v=yUPt7JuXvPk on 30/07/2021.

Kleijnen, J., Sanchez, S., Lucas, T., Cioppa, T., 2005. State-of-the-Art Review: A User's Guide to the Brave New World of Designing Simulation Experiments. INFORMS Journal on Computing 17 (3) 263-289 https://doi.org/10.1287/ijoc.1050.0136.

Law, A, 2015. Simulation Modelling and Analysis, Fifth Edition, 804pp. McGraw-Hill, New York.

Nance, R., Sargent, R. G., 2002. Perspectives on the Evolution of Simulation. Operations Research 50 (1) 161 172 https://doi.org/10.1287/opre.50.1.161.17790.

Privratsky, K. L., Thompson, J., 2016. Logistics in the Falklands War: A Case Study in Expeditionary Warfare. Pen \& Sword Books Limited, Havertown.

Sanchez, S., Sanchez, P., \& Wan, H. (2020). Work Smarter, Not Harder: A Tutorial on Designing and Conducting Simulation Experiments, In: 2020 Winter Simulation Conference (WSC), 1128-1142, https://doi.org/10.1109/WSC48552.2020.9384057.

Sargent, R. G., 2013. Verification and validation of simulation models. Journal of Simulation 7 (1) 12-24, https://doi.org/10.1057/jos.2012.20. 